\title{
Effects of Reduction in Construction Temperature on Workability of Warm Mix Asphalt Incorporating Rh- wma Additive
}

\author{
Bashir M. Aburawi* \\ Department of Civil, College of Engineering, Elmergib University, Libya \\ DOI: https://doi.org/10.21467/proceedings.4.6 \\ * Corresponding author email: Aburawi2018@gamil.com
}

\begin{abstract}
Conventional Hot Mix Asphalt (HMA) has been the primary material used in pavement in past decades. Recently, compared to conventional HMA, Warm Mix Asphalt (WMA) has shown great potential and offers benefits not given by HMA, since the WMA can be produced at lower temperatures without affecting pavement performance. The WMA technologies allow a significant reduction in construction temperatures of asphalt mixtures through lowering the viscosity of binders. In WMA, different types of additives are added to the binder depending on the technology used and such addition of these materials brings down the viscosity drastically thus reducing the temperature to which the aggregates and binders have to be heated during mixing and compaction. This study was limited to the effects of construction temperature on the workability performance of WMA incorporating RH-WMA additive. Binder namely 80/100 was used for preparation of all asphalt mixtures and RH-WMA used as warm mix asphalt additive. Asphalt mixtures were prepared using crushed granite aggregate for AC14 wearing course and compacted by using Servopac Gyratory Compactor (SGC). The Leeds Workability Method used to determine the workability index. The results show that increase in construction temperature improves the workability of both WMA and HMA. Workability Index (WI) of mixtures incorporating 3\% RH-WMA is slightly higher than mixtures incorporating 2\% RH-WMA. The increase in WI is more pronounced at higher RH-WMA contents.
\end{abstract}

Keywords: Warm Mix Asphalt, RH-WMA, Servopac Gyratory Compactor, The Leeds Workability Method, Workability Index.

\section{Introduction}

Asphalt is a pavement material that is brittle and hard in cold environments and soft at elevated temperatures. It has been historically employed as the most popular paving material for roadways [1]. Traditionally, Hot Mix Asphalt (HMA) has been widely used for road construction. The HMA production process requires a high temperature application. This requires the aggregates to be heated to very high temperature. The major disadvantage

(C) 2018 Copyright held by the author(s). Published by AIJR Publisher in Proceedings of First Conference for Engineering Sciences and Technology (CEST-2018), September 25-27, 2018, vol. 2.

This is an open access article under Creative Commons Attribution-NonCommercial 4.0 International (CC BY-NC 4.0) license, which permits any non-commercial use, distribution, adaptation, and reproduction in any medium, as long as the original work is properly cited. ISBN: 978-81-936820-6-7 
associated with this process is that it consumes a lot of energy and discharges a large volume of toxic gasses and dust during its production and paving process. This has adverse effects on the health of the construction workers as well as the environment in particular.

Since Warm Mix Asphalt (WMA) additives can reduce the binder viscosity, the production temperatures can be lowered, compared to conventional HMA. It was reported that the mixing temperatures of WMA ranged from $100^{\circ} \mathrm{C}$ to $140^{\circ} \mathrm{C}$ compared to the mixing temperatures of $150^{\circ} \mathrm{C}$ to $180^{\circ} \mathrm{C}$ for conventional HMA [2]. Compared with HMA, WMA technology can significantly reduce mixing temperatures of asphalt mixture by $20^{\circ} \mathrm{C}$ to $30^{\circ} \mathrm{C} \mathrm{[3].} \mathrm{One} \mathrm{of} \mathrm{the}$ additives used to produce WMA is a type of wax named RH-WMA. The additives improved asphalt binder coating, mixture workability and compactability at lower temperatures. Hesami [4] defined the workability of asphalt as the ease of handling, paving and compacting the mixture. Asphalt mixtures with higher workability are known to have higher compactability.

\subsection{Warm Mix Asphalt Technology}

To overcome the disadvantages associated with HMA, the WMA technology was introduced. WMA improves the energy efficiency by reducing the construction temperature. WMA uses additives that help reduce the viscosity of the asphalt binder, which in turn causes the asphalt mixing and construction to be carried out at relatively low temperatures while maintaining its performance similar to HMA [5]. Figure 1 shows different types of WMA additives and Figure 2 shows the other advantages of using WMA.

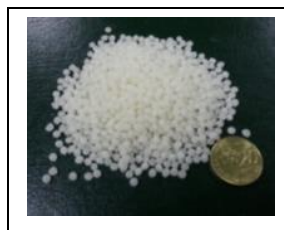

Sasobit ${ }^{\circledR}$
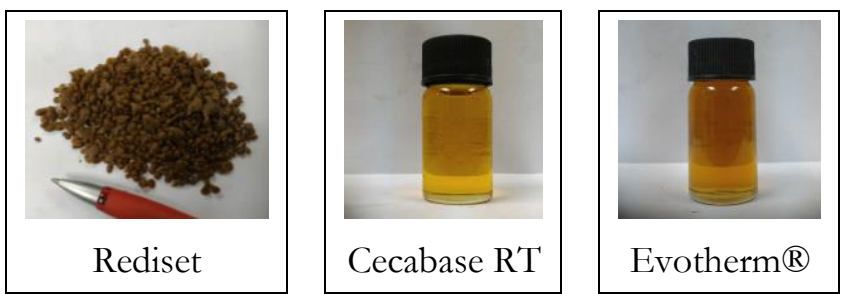

Figure 1: Types of WMA Additives
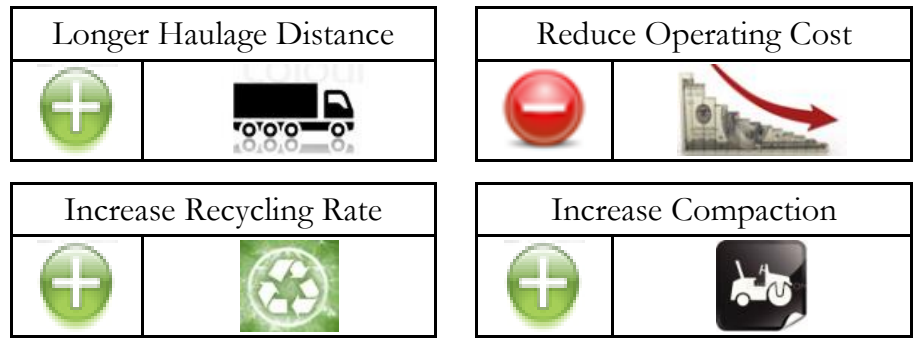

Figure 2: Advantages of WMA
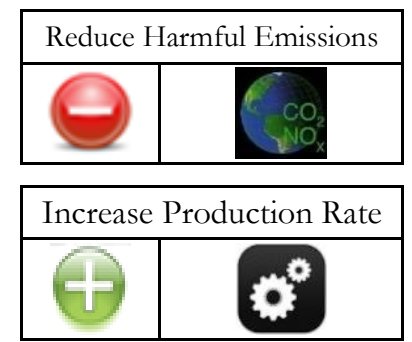

One of the major advantages of WMA is the increased workability at conventional and lower compaction temperatures. Bennert. [6] defined the workability as the property of the asphalt mixture that describes the ease with which asphalt mixture can be placed and compacted to the desired mat density. Abdelgalil et al. [7] used a device that employed an electric transducer and heat regulator for evaluating mixing temperature in mixture workability and compatibility by determining the correlation between workability and compatibility. Zhao and Guo [8]

Proceedings of First Conference for Engineering Sciences and Technology (CEST-2018), vol. 2 
Effects of Reduction in Construction Temperature on Workability of Warm Mix Asphalt Incorporating Rh-wma Additive

developed a test instrument to measure asphalt mixture workability. From the torque, the workability of the mixture can be judged and at lower mixing temperature, WMA exhibits similar workability with HMA [9]. Foaming materials can be used to produce WMA to increase the workability and compactibility of the mixture at lower temperatures [10]. Xiao. [11] reported that chemical additives improve asphalt binder coating, mixture workability and compactibility at lower temperatures. To lower the mixing temperature, organic or wax additives are utilised for reducing the viscosity of binder [12].

\section{Materials and Methods}

\subsection{Materials}

The conventional virgin 80/100 asphalt binder used was obtained from Shell Bitumen Company, Singapore and used as the control binder.Granite aggregate used in the preparation of all the mixtures were supplied by Kuad Kuari in Penang. The crushed granite was used in the mix design for Asphaltic Concrete mixture AC14 wearing course mix according to the Malaysian Public Works Department local specifications [13]. Aggregates and asphalt binder with properties similar to those used by Hamzah et al. [14] were also utilized for this study.

Pavement Modifier (PMD) was the filler used in this study. The PMD modifier was supplied by NSL Chemicals Ltd, Ipoh, Perak, Malaysia [15]. Figure 3 shows the PMD filler used. The RH-WMA warm mix modification technology was used to prepare WMA. RH-WMA is an organic based additive like wax developed in China. It can be utilized as an additive to be blended with reclaimed asphalt binder [16]. Figure 4 shows the RH-WMA that exists in the form of small white particles. The mixtures were compacted using the Servopac gyratory compactor (SGC) as shown in Figure 5 at 30 gyrations per minute at a compaction angle of

$1.25^{\circ}$ for 100 gyrations.

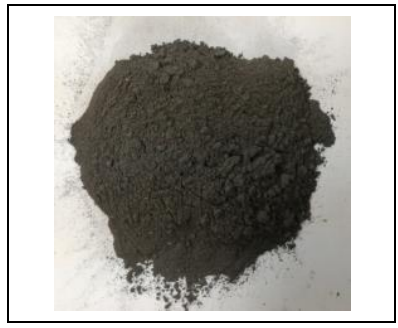

Figure 3: $P M D$ as Filler

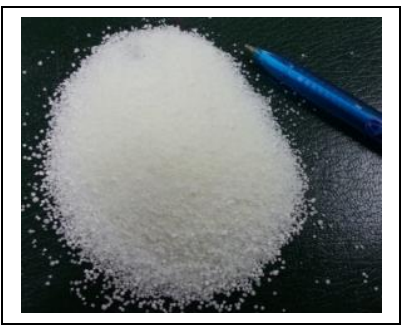

Figure $4: R H-W M A$ as Additive for $W M A$

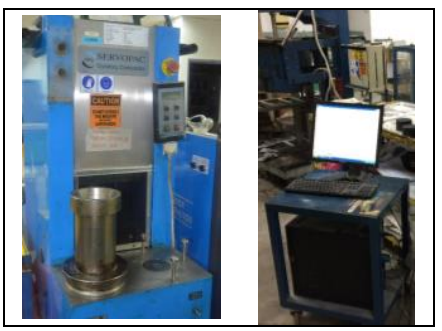

Figure 5: Servopac Gyratory

Compactor

\subsection{Leeds Workability Method}

Asphalt mixtures must be workable so that it can be easily handled, spread and compacted to the required density. Unworkable mixtures will be difficult to compact without tearing under the paving machine screed and hence adequate compaction will not be achieved.

The Leeds Workability Method was developed by Cabrera and Dixon [17]. It was based on the relationship between mixture porosity and the associated compaction energy input applied by the Gyratory Testing Machine (GTM). Under the same field compaction effort, mixes with 
higher Workability Index (WI) shall lead to easy compaction and higher density compared to those with low workability. Mixes that achieve higher WI (workability) and lower CEI (compactability) are desirable. Higher WI is associated with easier and faster mat compaction during construction and lower CEI is associated with higher stability during trafficking. The WI can be used effectively to assess the influence of compaction temperature or mix composition, particularly binder content, coarse aggregate content, sand morphology and filler type [17]. Field experience has shown that mixes with a WI equal to or smaller than 6 are difficult to handle and compact. The mixtures were compacted at their OBC using the SGC. This compaction type is expected to realistically simulate the compaction in the field as compared to the impact compactor like Marshall compaction. Height changes and the number of its gyrations can be automatically recorded.

A high WI indicates a more workable mixture or mixture that is easier to compact. From the semi-logarithmic plot, air voids reduce with the number of gyrations. The straight line equation is defined in Equation (1).

$$
\mathrm{Y}=\mathrm{A}-\mathrm{Bx}
$$

Where:

$$
\begin{aligned}
& \mathrm{Y}=\text { Air voids, }(\%) \\
& \mathrm{A}, \mathrm{B}=\text { Constant } \\
& \mathrm{x} \quad=\text { Log10, number of gyration }
\end{aligned}
$$

From Equation (2), the constant A is obtained by extrapolating the straight line to intersect with the Y-axis at zero gyration. The WI is defined as in Equation (2).

$$
\mathrm{WI}=100 / \mathrm{A}
$$

\section{Results and Discussion}

\subsection{Effects of Compaction Temperature on Workability Index}

The results show that increase in compaction temperature improves the workability of both WMA and HMA. This is true for all WMAs which demonstrate better workability than HMA. The compaction temperature of $125^{\circ} \mathrm{C}$ has a significant influence on the workability of WMA. It can be seen from Figure 7 that, as the number of gyrations increase, there is difference in the air voids of all mixtures. From Figure 7 (a) and (b), the air voids are highest for HMA and is more pronounced at 100 gyrations. This also infers that at $125^{\circ} \mathrm{C}$ and $110^{\circ} \mathrm{C}$ compaction temperatures, the increase in the number gyrations can result in lower air voids. This is not true for other temperatures as shows by no significant difference in Figure 7 (c) at $95^{\circ} \mathrm{C}$ compaction temperature. According to Figure 7 (c), there is no major changes in the air voids between HMA and WMA. The use of WMA additives has shown no significant benefit at $95^{\circ} \mathrm{C}$ compaction temperature. The WMA $2 \%$, WMA 3\% and HMA curves follow similar trend. 
Effects of Reduction in Construction Temperature on Workability of Warm Mix Asphalt Incorporating Rh-wma Additive

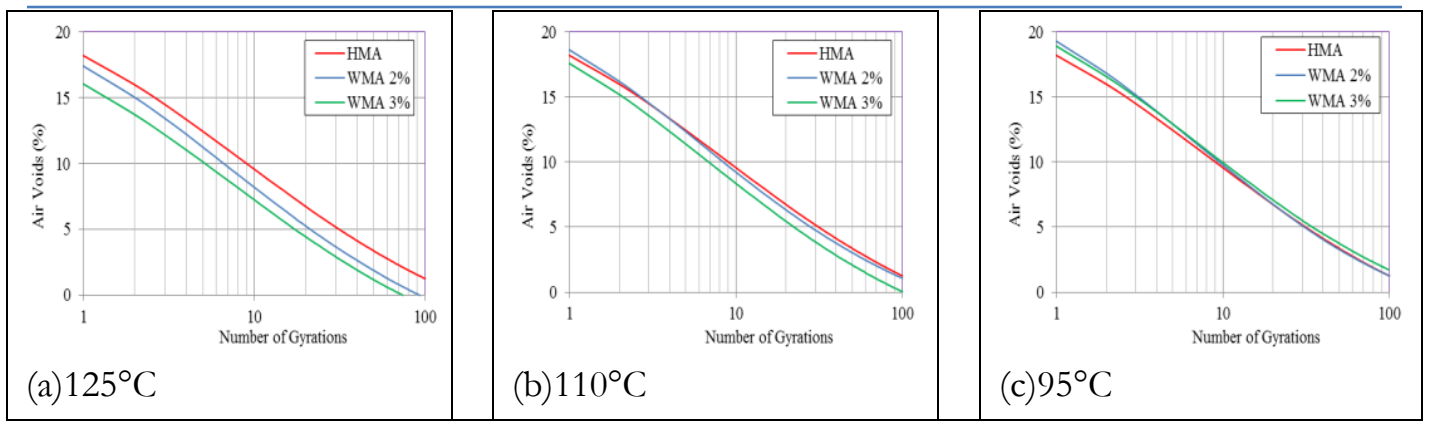

Figure 7 : Air Voids for WMA Compacted at Various Temperatures (HMA Compacted at $150^{\circ} \mathrm{C}$ )

All straight lines are plotted for every sample to determine the average WI. The regression value, $\mathrm{R}^{2}$ for the straight line is above 0.90 , implying good accuracy regression equations.

The effect of compaction temperature on WI can be seen by comparing WI in Figure 8. The WI increases as compaction temperature increases. The increase in WI with the increase in compaction temperature is due to the lubricating effects of asphalt mixture keeping the viscosity of the binder suitable for compaction. Higher WI values are preferred and are indicative of better mix workability. Mixture compacted at $125^{\circ} \mathrm{C}$ exhibited better workability than HMA. WMA has better workability characteristics than HMA. The WI reduces by 3$16 \%$, for mixtures incorporating $2 \% \mathrm{RH}-\mathrm{WMA}$ when compaction temperature reduces to $110^{\circ} \mathrm{C}$ and $95^{\circ} \mathrm{C}$, respectively. $3-19 \%$ for mixtures incorporating $3 \% \mathrm{RH}-\mathrm{WMA}$ when compaction temperature reduces to $110^{\circ} \mathrm{C}$ and $95^{\circ} \mathrm{C}$, respectively.

\subsection{Effects of RH-WMA Content on Workability}

From Figure 8, the average WI of mixtures incorporating 3\% RH-WMA is slightly higher than mixtures incorporating 2\% RH-WMA. The increase in WI is more pronounced at higher RHWMA contents.

\subsection{Correlation between CEI and WI}

Figure 9 shows the relationship between CEI and WI for different mixtures. Mixtures with high WI reflects low CEI and have better workability. Figure 9 shows linear relationships between CEI and WI. The WI is inversely proportional to CEI. High WI and low CEI are desirable.

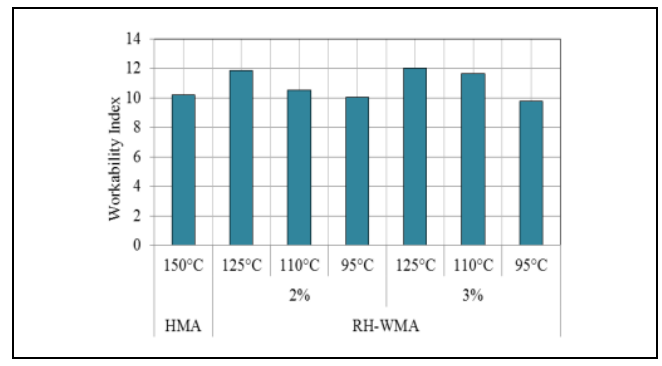

Figure 8: WI of Asphalt Mixtures Tested

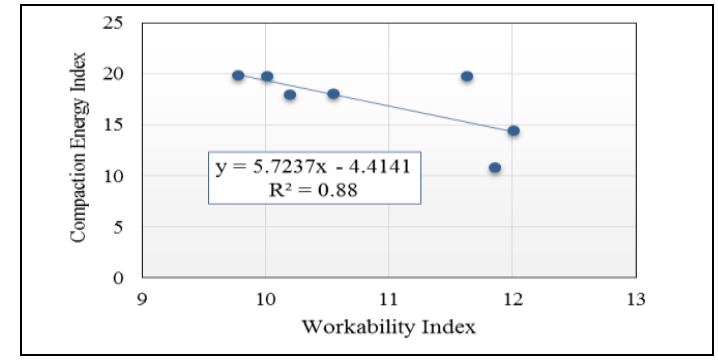

Figure 9: Correlation between CEI and WI 


\section{Conclusions}

The RH-WMA additive would either reduce the viscosity of the binder or allow better workability of the mix at lower binder content. For this case, the OBC of WMA is slightly lower than the OBC for HMA. The WI can be used effectively to assess the influence of production temperature.

\section{Acknowledgment}

The author would like to acknowledge the Universiti Sains Malaysia that has funded this research grant through the Research University Grant Scheme which enables this paper to be written.

\section{References}

[1] Sulyman, M., Sienkiewicz, M. and Haponiuk, J. Asphalt Pavement Material Improvement: A Review. International Journal of Environmental Science and Development, 5, 444-454, 2014.

[2] Kim, Y.-R., Zhang, J. and Ban, H.Moisture Damage Characterization of Warm-Mix Asphalt Mixtures Based on Laboratory-Field Evaluation. Construction and Building Materials, 31, 204-211, 2012.

[3] Wang, C., Hao, P., Ruan, F., Zhang, X. and Adhikari, S. Determination of the Production Temperature of Warm Mix Asphalt by Workability Test. Construction and Building Materials, 48, 1165-1170, 2013

[4] Hesami, E., Jelagin, D., Kringos, N. and Birgisson, B. An Empirical Framework for Determining Asphalt Mastic Viscosity as A Function of Mineral Filler Concentration. Construction and Building Materials, 35, 23-29, 2012.

[5] Kim, H., Jeong, K.-D., Lee, M. S. and Lee, S.-J. Performance Properties of CRM Binders with Wax Warm Additives. Construction and Building Materials, 66, 356-360, 2014.

[6] Bennert, T., Reinke, G., Mogawer, W. and Mooney, K. Assessment of Workability and Compactability of WarmMix Asphalt. Transportation Research Record: Journal of the Transportation Research Board, 2180(1), 36-47, 2010.

[7] Abdelgalil, S. M. K., Abdul Rahman, M. and Arshad, A. K. Development of Workability Measuring Device for Asphalt Mixture Using Electronic Transducer and Temperature Regulator. Journal of Basic and Applied Scientific Research, 1, 721-726, 2011.

[8] Zhao, G.-J. and Guo, P. Workability of Sasobit Warm Mixture Asphalt. Energy Procedia, 16, 1230-1236, 2012.

[9] Gudimettla, J. M., Cooley, L. A. and Brown, E. R. Workability of Hot Mix Asphalt. National Center for Asphalts Technology, Report, 03-03, 2003

[10] Martinez-Arguelles, G., Giustozzi, F., Crispino, M. and Flintsch, G. W. (2014). Investigating Physical and Rheological Properties of Foamed Bitumen. Construction and Building Materials, 72, 423-433, 2014.

[11] Xiao, F., Punith, V. S. and Amirkhanian, S. N. Effects of Non-Foaming WMA Additives on Asphalt Binders at High Performance Temperatures. Fuel, 94(5), 144-155, 2012.

[12] Sheth, N. M. Evaluation of Selected Warm Mix Asphalt Additives. Master Thesis, The University of Iowa, 2010.

[13] JKR. Standard Specification for Road Works in Malaysia, (Section 4: Flexible Pavements), Cawangan Jalan, Jabatan Kerja Raya Malaysia, Kuala Lumpur, 2008.

[14] Hamzah, M. O., Golchin, B. and Tye, C. T. Determination of the Optimum Binder Content of Warm Mix Asphalt Incorporating Rediset Using Response Surface Method. Construction and Building Materials, 47, 1328-1336,2013.

[15] Aman, M. Y. (2013). Water Sensitivity of Warm Porous Asphalt Incorporating Sasobit ${ }^{\circledR}$. Ph.D Thesis, Universiti Sains Malaysia.

[16] Wang, H., Dang, Z., You, Zhanping. and Cao, D. Effect of Warm Mixture Asphalt (WMA) Additives on High Failure Temperature Properties for Crumb Rubber Modified (CRM) Binders. Construction and Building Materials, 35, 281288,2012

[17] Cabrera, J.G., Dixon, J.R. Performance and Durability of Bituminous Material, Proceeding of Symposium,University of Leeds, 1994 